\title{
A Diet Enriched with the Omega-3 Fatty Acid Docosahexaenoic Acid Reduces Amyloid Burden in an Aged Alzheimer Mouse Model
}

\author{
Giselle P. Lim, ${ }^{1,3}$ Frédéric Calon, ${ }^{1,3}$ Takashi Morihara, ${ }^{1,3}$ Fusheng Yang, ${ }^{1,3}$ Bruce Teter, ${ }^{1,3}$ Oliver Ubeda, ${ }^{1,3}$ \\ Norman Salem Jr, ${ }^{5}$ Sally A. Frautschy, ${ }^{1,2,3,4}$ and Greg M. Cole ${ }^{1,2,3,4}$ \\ Departments of ${ }^{1}$ Medicine and ${ }^{2}$ Neurology, University of California Los Angeles, Los Angeles, California 90095, ${ }^{3}$ Veterans Affairs Greater Los Angeles \\ Healthcare System and ${ }^{4}$ Geriatric Research Educational Clinical Center, North Hills, California 91343, and ${ }^{5}$ Section of Nutritional Neuroscience, Laboratory \\ of Membrane Biochemistry and Biophysics, Division of Intramural Clinical and Biological Research, National Institute on Alcohol Abuse and Alcoholism, \\ National Institutes of Health, Rockville, Maryland 20852
}

Epidemiological studies suggest that increased intake of the omega-3 (n-3) polyunsaturated fatty acid (PUFA) docosahexaenoic acid (DHA) is associated with reduced risk of Alzheimer's disease (AD). DHA levels are lower in serum and brains of AD patients, which could result from low dietary intake and/or PUFA oxidation. Because effects of DHA on Alzheimer pathogenesis, particularly on amyloidosis, are unknown, we used the APPsw (Tg2576) transgenic mouse model to evaluate the impact of dietary DHA on amyloid precursor protein (APP) processing and amyloid burden. Aged animals (17-19 months old) were placed in one of three groups until 22.5 months of age: control (0.09\% DHA), low-DHA (0\%), or high-DHA (0.6\%) chow. $\beta$-Amyloid (A $\beta)$ ELISA of the detergent-insoluble extract of cortical homogenates showed that DHA-enriched diets significantly reduced total A $\beta$ by $>70 \%$ when compared with low-DHA or control chow diets. Dietary DHA also decreased A $\beta 42$ levels below those seen with control chow. Image analysis of brain sections with an antibody against $\mathrm{A} \beta$ (amino acids 1-13) revealed that overall plaque burden was significantly reduced by $40.3 \%$, with the largest reductions (40-50\%) in the hippocampus and parietal cortex. DHA modulated APP processing by decreasing both $\alpha$ - and $\beta$-APP C-terminal fragment products and full-length APP. BACE1 ( $\beta$-secretase activity of the $\beta$-site APP-cleaving enzyme), ApoE (apolipoprotein E), and transthyretin gene expression were unchanged with the high-DHA diet. Together, these results suggest that dietary DHA could be protective against $\beta$-amyloid production, accumulation, and potential downstream toxicity.

Key words: DHA; polyunsaturated fatty acid; A $\beta$; APP; secretase; Alzheimer

\section{Introduction}

The essential fatty acids, which include the omega-6 (n-6) and omega-3 (n-3) fatty acids, are crucial components of the diet. Docosahexanoic acid (DHA) is an $n-3$ polyunsaturated fatty acid (PUFA) found predominantly in marine fish and algae. Although it has a low conversion rate, it can also be biosynthesized in vivo in mammals from dietary n-3 sources, notably $\alpha$-linolenic acid (Salem et al., 1996b). It is essential for prenatal brain development and normal maintenance of brain function and vision in adults (Mitchell et al., 1998). Deficiencies in the level of DHA, such as

Received 0ct. 11, 2004; revised Feb. 8, 2005; accepted Feb. 9, 2005.

This work was supported by National Institute on Aging Grants NIA-AG13471 (G.M.C.) and NIA-AG16793 (S.A.F.) a Veterans Affairs merit award (G.M.C.), the Alzheimer Association (G.M.C.), and a Senior Research Fellowship from the Canadian Institutes of Health Research (F.C.). We acknowledge Karen Hsiao Ashe for her longtime collaboration, Jonathan Yao, Gloria Gutierrez, Juan Orozco, and Walter Beech for their excellent efforts with the transgenic mouse colony, and Mychica Simmons for assistance with histological image analysis.

Correspondence should be addressed to Dr. Gregory M. Cole, Greater Los Angeles Veterans Affairs Healthcare System, Geriatric Research, Education, and Clinic Center 11E, 16111 Plummer Street, Sepulveda, CA 91343. E-mail: gmcole@ucla.edu.

F. Calon's present address: Molecular Endocrinology and Oncology Research Center, Laval University Medical Center, Québec, Québec, G1V 4G2 Canada. E-mail: frederic.calon@crchul.ulaval.ca.

DOI:10.1523/JNEUROSCI.4225-04.2005

Copyright $\odot 2005$ Society for Neuroscience $\quad$ 0270-6474/05/253032-09\$15.00/0 low serum levels as well as high dietary intake ratios of n-6/n-3 fatty acids, have been linked to cognitive impairment (Connor et al., 1990; Suzuki et al., 1998; Kyle et al., 1999; Gamoh et al., 2001; Ikemoto et al., 2001; Catalan et al., 2002) and Alzheimer's disease (AD). The brain membranes of $\mathrm{AD}$ patients have been found to be deficient in DHA (Soderberg et al., 1991; Prasad et al., 1998). The loss of DHA in AD may reflect its propensity for free radicalmediated lipid peroxidation (because of its six double bonds), resulting in its conversion to neuroprostanes (F-4 isoprostanes), which are elevated in AD (Nourooz-Zadeh et al., 1999; Montine et al., 2002). Decreased dietary intake and increased oxidative stress could contribute to brain DHA depletion and low blood levels in AD patients. Several epidemiological studies show a protective effect associated with increased fish consumption and intake of unsaturated fats leading to low n-6/n-3 fatty acid ratios (Kalmijn et al., 1997; Barberger-Gateau et al., 2002; Grant et al., 2002; Yamada et al., 2002; Morris et al., 2003; Kalmijn et al., 2004). Thus, it seems that n-3-rich diets may be beneficial in reducing risk for $A D$, but it is unclear how n-3 impacts $A D$ pathogenesis and whether DHA is the preventive dietary factor in fish oil.

Feeding n-3-depleted diets to multiple generations of animals 
limits their learning ability, but learning is restored when they are switched to diets supplemented with DHA (Connor et al., 1990; Suzuki et al., 1998; Gamoh et al., 2001; Ikemoto et al., 2001; Moriguchi and Salem, 2003). This adverse effect on CNS function in the absence of neurodegenerative pathology may contribute to increased $\mathrm{AD}$ risk. DHA or its enzymatically generated metabolites may be neuroprotective by reducing $\beta$-amyloid $(\mathrm{A} \beta$ ) toxicity (Mukherjee et al., 2004). Consistent with this view, preadministration of DHA in $\mathrm{A} \beta$-infused rats protected against neuronal apoptosis and was beneficial in reducing $n-6 / n-3$ ratios and the decline of learning ability (Hashimoto et al., 2002). Furthermore, DHA depletion caused AD-like phosphatidylinositol 3 kinase (PI3K) deficits and enhanced behavioral deficits in a transgenic (Tg) model (Calon et al., 2004). It is unknown whether some of these beneficial effects of DHA occur because of direct effects on $\mathrm{A} \beta$, the causal factor in $\mathrm{AD}$, such as limiting $\mathrm{A} \beta$ production, aggregation, and accumulation. Therefore, the purpose of this study was to evaluate the impact of DHA on $\mathrm{A} \beta$ production and amyloid precursor protein (APP) processing in the Tg2576 mouse.

\section{Materials and Methods}

Animal treatment groups. Seventeen- to 19-month-old male and female Tg2576 mice were placed on one of three diets: (1) control chow (Purina 5015 breeder chow; Purina Mills, St. Louis, MO) was the standard chow on which all animals were raised (n-6/n-3 ratio of 7:1); (2) a DHAdepleting low n-3 PUFA test diet adequate in all other nutrients that we called "low-DHA" diet [n-6/n-3 ratio of 85:1; TD00522 (Harlan Teklad, Madison, WI) with $6 \%$ fat as safflower oil]; or (3) low-DHA diet supplemented with $0.6 \%$ DHA (Martek Bioscience, Columbia, MD), which we referred to as "high-DHA" diet (TD01200) (Calon et al., 2004). Mice were fed control chow $(0.09 \%$ DHA; $n=8)$, low-DHA chow ( $0 \%$ DHA; $n=6)$, or high-DHA chow ( $0.6 \%$ DHA; $n=6)$ for an average of $103 \pm$ $5 \mathrm{~d}$ before being killed at 22.5 months of age. After animals were perfused with HEPES buffer, brain regions were dissected from one hemisphere as described previously (Lim et al., 2000). Biochemical measurements were performed in the residual cortex (cortex region without frontal, entorhinal, or piriform areas, which were used for confirmation of DHA depletion and the absence of presynaptic marker loss). The other brain hemisphere was fixed in $4 \%$ paraformaldehyde and processed for immunohistochemistry.

Tissue preparation. Tissue samples were processed in TBS (soluble fraction) and lysis buffer (membrane fraction) containing protease inhibitor mixtures as described previously (Lim et al., 2001; Calon et al., 2004). Briefly, brain tissue was homogenized and sonicated in TBS. The insoluble pellet was then sonicated in lysis buffer $(150 \mathrm{~mm} \mathrm{NaCl}, 10 \mathrm{~mm}$ $\mathrm{NaH}_{2} \mathrm{PO}_{4}, 1$ mm EDTA, $1 \%$ Triton X-100, 0.5\% SDS, and 0.5\% deoxycholate) containing the same protease inhibitor mixture. The resulting homogenate was subjected to ultracentrifugation, and the lysis-soluble supernatant was collected and frozen. To analyze the detergent-insoluble $\mathrm{A} \beta$, the lysis-insoluble pellet was sonicated in $8 \mathrm{vol}$ of $5 \mathrm{~m}$ guanidine and $50 \mathrm{~mm}$ Tris- $\mathrm{HCl}$ and solubilized by agitation at room temperature for $3-4 \mathrm{~h}$.

Fatty acid analysis. Fatty acid analysis in the frontal cortex was performed using the Folch method (Moriguchi et al., 2000) and gas chromatography with flame ionization detection, as reported previously (Salem et al., 1996a; Calon et al., 2004).

$A \beta$ levels. The sandwich ELISA for total $\mathrm{A} \beta$ has been described previously using monoclonal antibodies $4 \mathrm{G} 8$ for capture and 10G4 for detection (Lim et al., 2000). To measure detergent-insoluble $\mathrm{A} \beta$, a 1:10,000 dilution of the guanidine-soluble extracts was made with TBS containing $5 \%$ BSA and $1 \times$ protease inhibitor mixture (catalog \#539131; Calbiochem, La Jolla, CA) and centrifuged at $16,000 \times g$ for $20 \mathrm{~min}$ at $4^{\circ} \mathrm{C}$. Samples were loaded in triplicate $(100 \mu \mathrm{l})$. Soluble $\mathrm{A} \beta$ was measured in the TBS-soluble fraction $(24 \mu \mathrm{g}) . \mathrm{A} \beta 40$ and $\mathrm{A} \beta 42$ levels were measured using ELISA (catalog \#KHB3482 and \#KHB3442; Biosource, Camarillo, $\mathrm{CA}$ ) in guanidine fractions diluted 1:10,000 in sample diluent provided by manufacturer. Data was analyzed using one-way ANOVA (treat- ment), and Bartlett's test for homogeneity of variance was also performed to determine whether variances were equal. $p$ values $\leq 0.05$ were considered significant.

Image analysis of plaque pathology. Plaque burden was assessed using a characterized polyclonal antibody against $\mathrm{A} \beta 1-13$ (DAE) (Lim et al., 2000). Immunolabeling was examined in the entorhinal cortex, perirhinal cortex, parietal cortex, retrosplenal-frontal cortex, and hippocampal areas of animals on low-DHA $(n=4)$ and high-DHA $(n=5)$ diets. A mean area of $7.87 \mathrm{~mm}^{2}$ was examined on three coronal sections (bregma $-2.06 \mathrm{~mm}$ ) from each mouse. Plaque burden was calculated by dividing total area of $\mathrm{A} \beta$-positive structures by total area of region analyzed (in square micrometers). All images were acquired from a Nikon (Tokyo, Japan) E800 microscope with a Sony (Tokyo, Japan) DXC-390 3CCD video system. The video signal was routed into a Macintosh computer (Apple Computers, Cupertino, CA) via a Scion (Frederick, MD) AG-5 averaging frame grabber, and these digitized images were analyzed with $\mathrm{NIH}$ Image software (version 1.62c). Custom Pascal macro subroutines were written to calculate various parameters of DAE, such as number of small and large plaques, mean area, total area of plaques, and plaque burden.

Immunoblot of full-length APP. Samples from TBS (cytosol) and lysis buffer (membrane) fraction ( $30 \mu \mathrm{g}$ of protein) were electrophoresed on $10 \%$ acrylamide gels and transferred ( $400 \mathrm{~mA}$ for $210 \mathrm{~min}$ ) to Immobilon polyvinylidene difluoride (PVDF) membranes (Millipore, Bedford, MA) before blocking in $10 \%$ nonfat dry milk and $0.1 \%$ gelatin in PBS for $1.5 \mathrm{~h}$. Blots were immunoblotted with N-terminal 22C11 (Chemicon, Temecula, CA) at 1:1000, followed by goat anti-mouse $(1: 10,000)$ and development with chemiluminescence (ECL; Amersham Biosciences, Piscataway, NJ). Band intensities were scanned and quantified with densitometric software (Molecular Analyst II; Bio-Rad, Hercules, CA).

Immunoblot of APP C-terminal fragments. Samples from membrane fraction $(20 \mu \mathrm{g})$ were separated using Novex (Wadsworth, $\mathrm{OH}$ ) precast gels (10-20\% Tris-tricine gel; Invitrogen, Carlsbad, CA) following the recommendations of the manufacturer. Proteins were transferred to a PVDF membrane for $3 \mathrm{~h}$, and blots were blocked in $10 \%$ nonfat dry milk and $0.1 \%$ gelatin in PBS for $1.5 \mathrm{~h}$ at $37^{\circ} \mathrm{C}$. APP C-terminal fragments (CTFs) were immunodetected with polyclonal rabbit anti-APP targeting C-terminal 20 residues (751-770) using a 1:5000 dilution (catalog $\# 171610$; Calbiochem) for $17 \mathrm{~h}$ at $4^{\circ} \mathrm{C}$. Standard for the APP C99 $\beta$-secretase-generated fragment was from APP null B103 neuroblastoma (D. Schubert, Salk Institute, San Diego, CA) stably transfected with pCEP4 $\beta$ C99 vector (T. Golde, Mayo Clinic, Jacksonville, FL). Blots were incubated in HRP-conjugated goat anti-mouse $(1: 30,000)$ for $60 \mathrm{~min}$ before development with ECL (Amersham Biosciences) or SuperSignal (Pierce, Rockford, IL). Bands were quantified using densitometric software (Molecular Analyst II), and ratios of CTF to full-length APP were analyzed using one-way ANOVA analysis (treatment) with Statview software.

Measurement of BACE1, transthyretin, and ApoE gene expression. Total RNA was prepared using RNAqueous kits (Ambion, Austin, TX). The absence of RNA degradation was confirmed by gel electrophoresis, and total RNA was DNase treated (DNA-free; Ambion). cDNA was generated from $1.4 \mathrm{mg}$ of total RNA in two reaction volumes of RETROscript (Ambion) using dT primer and then aliquoted for single uses. BACE1 ( $\beta$-secretase activity of the $\beta$-site APP-cleaving enzyme) and transthyretin (TTR) mRNA were measured using Assay on Demand kits Mm00478664_m1 and Mm00443267_m1, respectively (Applied Biosystems, Foster City, CA). ApoE (apolipoprotein E) mRNA was measured using primers TCTGACCAGGTCCAGGAAGAG and AGCTGTTCCTCCAGCTCCTTT and FAM-labeled probe CACACAAGAACTGACGGCACTGATGG. cDNA for relative standard curves was prepared from $\mathrm{Tg}-$ mouse brain with the same protocols with double RNA concentration in the reverse transcript step. Real-time PCR was performed by SDS7700 (Applied Biosystems) and TaqMan Universal PCR Master Mix (Applied Biosystems), using triplicates for samples and quadruplicates for standards. Glyceraldehyde-3-phosphate dehydrogenase (GAPDH) was measured as the internal control using TaqMan Rodent GAPDH control (Applied Biosystems). Consistent GAPDH levels confirm the absence of RNA and/or cDNA degradation (data not shown). 
The absence of contamination was checked using reverse transcription (RT) products made without Moloney murine leukemia virus reverse transcriptase. The $R^{2}$ of relative standard curves in TaqMan PCR was above 0.99. For optimum reliable comparisons, only sample values from the same PCR plate were statistically analyzed and are shown here.

\section{Results}

\section{CNS fatty acid profile reflects expected} changes with DHA depletion and repletion

DHA deficiency can be confirmed by assessing the levels of other C22 fatty acids that coordinately change in rodent brain in response to DHA depletion and repletion. For example, docosapentaenoic acid (DPA) (22:5n-6) shows a compensatory increase in rodent brain with DHA-deficient diets (Youyou et al., 1986; Salem et al., 2001). We reported previously that the DHA content in the frontal cortex of Tg2576 mice was depleted when animals were placed on this low-DHA diet paradigm, which resulted in DPA increasing 3.1-fold ( $p<0.001$ ), but with DHA, supplementation resulted in an 8.4-fold decrease $(p<0.0001)$ (Calon et al., 2004). Another 22 carbon fatty acid, adrenic acid, C22:4 (n-6), is also increased by DHA depletion and restored to normal levels by DHA supplementation (Ikemoto et al., 2001; Greiner et al., 2003). Hence, we measured the levels of adrenic acid in frontal cortex of all animals (Table 1). Adrenic acid was significantly increased by $15 \%$ in transgenic mice on low-DHA diets $(p<$ $0.01)$ compared with control diet; there was no significant increase in nontransgenic animals. When placed on high-DHA diets, adrenic acid levels decreased by $29-37 \%(p<0.0001)$. Therefore, adrenic acid changes were consistent with transgeneand diet-dependent DHA depletion that was restored with DHA supplementation.

\section{DHA lowers insoluble $A \beta$, but not soluble $A \beta$, in cortex}

To evaluate whether DHA can change amyloid levels, insoluble $\mathrm{A} \beta$ was measured in the guanidine-soluble extract. One-way ANOVA demonstrated a significant treatment effect between animals on low-DHA diet and high-DHA diet, in which DHA lowered the level of amyloid by $77 \%(p<0.05)$ (Fig. $1 A)$. Despite high DHA decreasing insoluble amyloid levels compared with low DHA, levels in the low-DHA group were not significantly different from levels seen in the control group $(p=0.06)$. Soluble $\mathrm{A} \beta$ was also measured from the TBS-soluble fraction of the same three groups. There was a $38 \%$ reduction in soluble $A \beta$ in the high-DHA group when compared with low-DHA mice, but statistical analysis showed that this difference was not significant $(p=0.50)$ (Fig. $1 B$ ).

\section{$\mathrm{A} \beta 42$ and $\mathrm{A} \beta 40$ levels are also lowered by DHA treatment} C-terminus antibodies specific for $A \beta 42$ and $A \beta 40$ were used to determine how DHA was affecting $\mathrm{A} \beta 40$ and $\mathrm{A} \beta 42$ in the cortex. One-way ANOVA analyses of both $A \beta 40$ and $A \beta 42$ in the guanidine-soluble fraction showed treatment effects between low-DHA and high-DHA animals. A $\beta 42$ levels were significantly reduced by $49.1 \%$ in the high-DHA group compared with the low-DHA group $(p<0.01$ ) (Fig. $1 C$ ) and reduced by $53.6 \%$ comparing high DHA with control group $(p<0.001)$. However, low-DHA and control group A $\beta 42$ levels were not significantly different, as was observed with total insoluble $\mathrm{A} \beta$ results. Interestingly, $A \beta 40$ levels were significantly increased by $65 \%$ in the low-DHA group when compared with the control group $(p<$
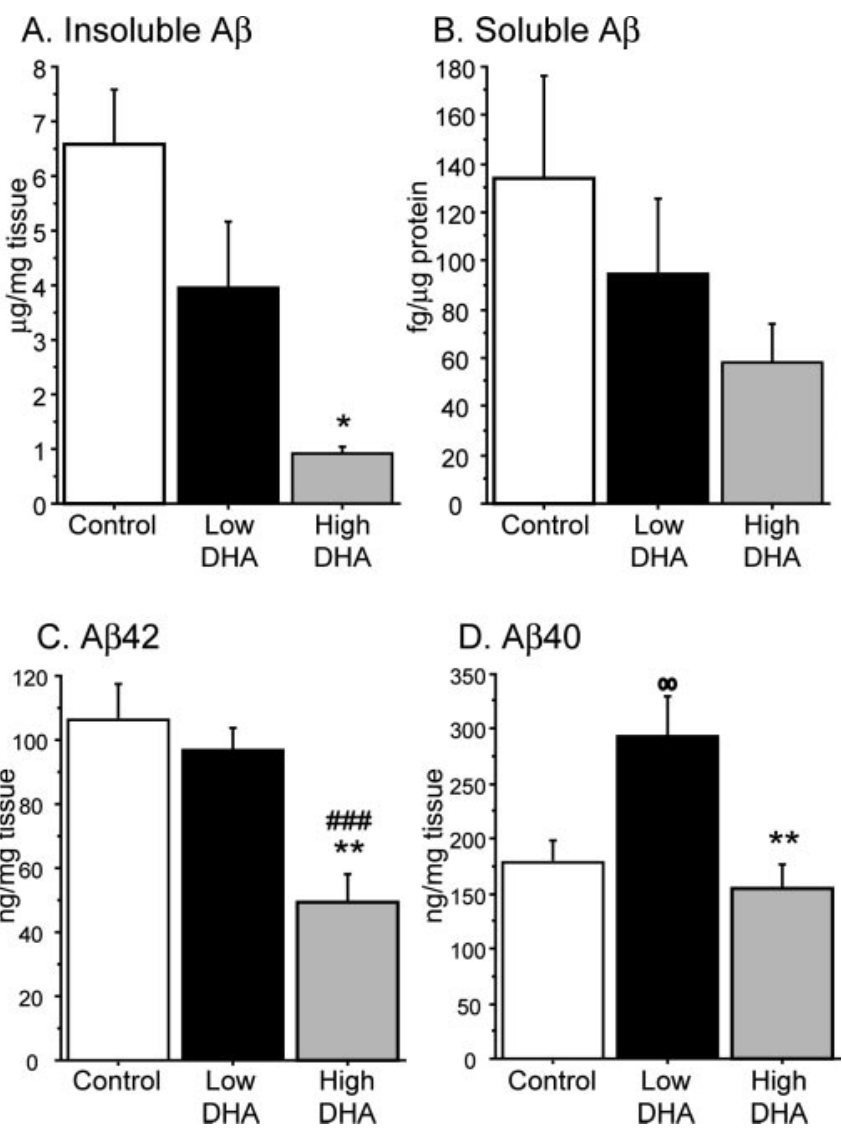

Figure 1. Detergent-insoluble amyloid (total $A \beta, A \beta 42$, and $A \beta 40$ ) is reduced in cortex of animals fed DHA-enriched diets. $A$, Detergent-insoluble amyloid measurements in cortex. Total $A \beta$ ELISA was performed on guanidine-soluble amyloid from cortices of low-DHA $(n=6)$ and high-DHA $(n=6)$ groups. Error bars represent SE. ${ }^{*} p<0.05$ compared with low-DHA group. $\boldsymbol{B}$, Soluble amyloid measurements in cortex. Total $A \beta$ ELISA was performed on TBS-soluble fractions (24 $\mu \mathrm{g}$ ) of the same two groups of animals. Error bars represent SE. C, A $\beta 42$ measurements in cortex. $A \beta 42$ ELISA (Biosource) was performed on guanidine-soluble fractions in cortices of animals fed control $(n=8)$, low-DHA $(n=6)$, and high-DHA $(n=6)$ diets. ${ }^{* *} p<$ 0.01 compared with low-DHA group; ${ }^{\# \#} p<0.001$ compared with control diet group. Error bars represent SE. D, A $\beta 40$ ELISA (Biosource) was used to measure levels of $A \beta 40$ in cortices of the same three groups of animals. ${ }^{\circ} p<0.01$ compared with control group; ${ }^{* *} p<0.01$ compared with low-DHA group. Error bars represent SE.

0.01) (Fig. 1D). High-DHA diet decreased A $\beta 40$ by $47.5 \%$ ( $p<$ 0.01 ), comparable with levels seen in the control group.

\section{DHA lowers plaque burden}

To determine whether DHA was reducing plaque burden, tissue sections from low-DHA and high-DHA mice were stained with an antibody against $A \beta 1-13$. Image analysis was performed on hippocampus, frontal cortex, parietal cortex, entorhinal cortex, and perirhinal cortex regions. ANOVA showed a significant overall treatment effect, in which plaque burden was lowered by 
A. Plaque burden

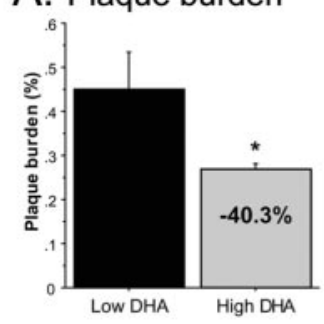

B. Plaque numbers
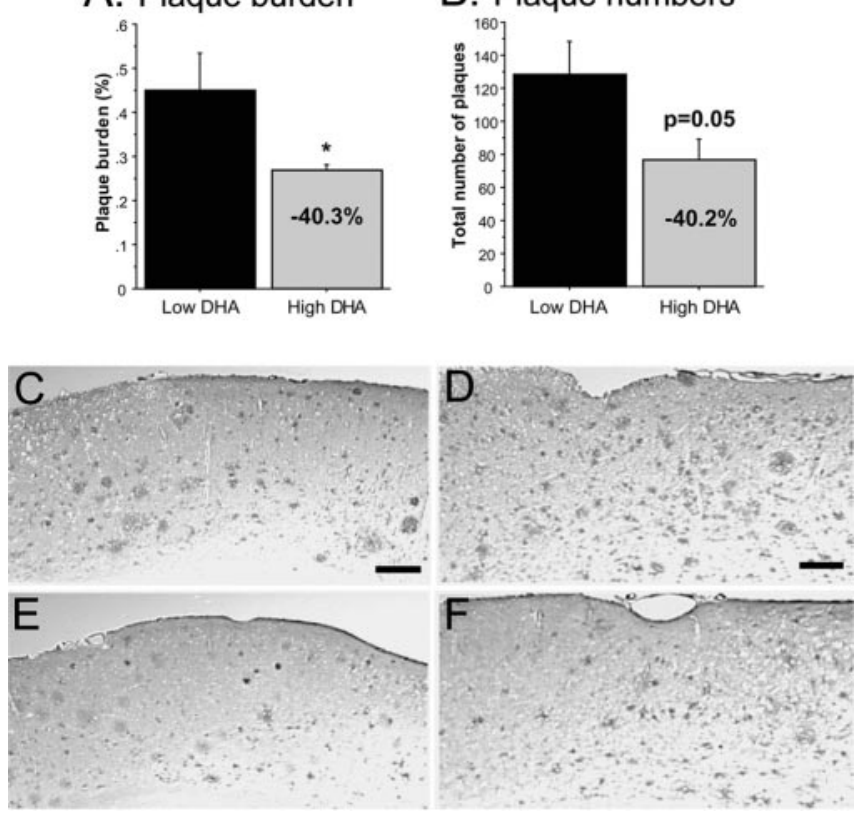

Figure 2. DHA lowers plaque burden. $\boldsymbol{A}$, Treatment effect on plaque burden. Hemibrain cryostat sections (12 $\mu \mathrm{m}$; bregma -2.06 ) were labeled with an antibody against $\mathrm{A} \beta 1-13$. Image analysis was performed on hippocampus and entorhinal, piriform, parietal, and retrosplenal-frontal cortex from low-DHA and high-DHA $(n=6)$ animals. One-way ANOVA showed an overall treatment effect for reducing plaque burden $(p<0.05)$. Error bars represent SE. ${ }^{*} p<0.05$. $\boldsymbol{B}$, Treatment effect of DHA on plaque numbers in Tg2576 mice. The graph depicts the mean plaque numbers (small and large plaques) and percentage change between low-and high-DHA animals. Error bars represent SE. $\boldsymbol{C}-\boldsymbol{F}$ are representative low-magnification images from low-DHA $(\boldsymbol{C}, \boldsymbol{D})$ and high-DHA $(\boldsymbol{E}, \boldsymbol{F})$ mice. $\boldsymbol{C}$ and $\boldsymbol{E}$ are from parietal cortex (scale bar, $35 \mu \mathrm{m}$ ), and $\boldsymbol{D}$ and $\boldsymbol{F}$ are from perirhinal cortex (scale bar, $30 \mu \mathrm{m}$ ).

Table 2. Effect of DHA on plaque burden in various regions of Tg2576 mice

\begin{tabular}{llll}
\hline Region & Low DHA & \multicolumn{1}{l}{ High DHA } & \% Change \\
\hline Entorhinal cortex & $0.352 \pm 0.11$ & $0.348 \pm 0.12$ & \multicolumn{1}{l}{ NS } \\
Hippocampus & $0.335 \pm 0.14$ & $0.204 \pm 0.04$ & $-39.1 \%$ \\
Parietal cortex & $0.393 \pm 0.07$ & $0.200 \pm 0.04$ & $-49.1 \%$ \\
Perirhinal cortex & $0.968 \pm 0.29$ & $0.51 \pm 0.08$ & $-47.3 \%$ \\
Frontal cortex & $0.372 \pm 0.06$ & $0.421 \pm 0.13$ & $+13.2 \%$ \\
\hline
\end{tabular}

This table illustrates the mean plaque burden in each brain region. Units are percentage of area stained by anti-A $\beta$ antibody. SEs are given. NS, Not significant.

$\sim 40 \%$ in sections from high-DHA mice $(p<0.05)$ (Fig. $2 A$ ). The total number of plaques also decreased by $40 \%$ in high-DHA mice (Fig. 2B). These reductions can be seen in lowmagnification photos of cortical areas from brains of low-DHA and high-DHA group mice (Fig. $2 C-F$ ). The largest reductions in plaque burden (40-50\%) occurred in the hippocampus and perirhinal and parietal cortex, brain regions that are vulnerable in $\mathrm{AD}$ (Table 2).

\section{Transthyretin and ApoE expression levels are unchanged with diet}

DHA may regulate $\mathrm{A} \beta$ clearance by modulating expression of amyloid binding proteins TTR and ApoE. Therefore, the cortical TTR and ApoE mRNA levels were measured as a function of diet, but, surprisingly, no changes were found (data not shown)

\section{DHA can alter levels of full-length APP and $\beta$ - and $\boldsymbol{\alpha}$-secretase products}

Because DHA reduced the detergent-insoluble amyloid and plaque burden, we evaluated whether DHA altered APP process- ing because secretase pathways are influenced by their lipid environments. To determine whether DHA changed the amount of secreted full-length APP, immunoblots from the TBS-soluble and lysis fractions of mice on control, low-DHA, and high-DHA diets were probed with 22C11 APP antibody that recognizes an extracellular N-terminal domain. Bands identified as secreted full-length APP were increased in low-DHA mice compared with control mice, consistent with increased proteolytic activity (Fig. $3 A$ ). Supplementing DHA in the diet restored levels comparable with those seen with control diet. Conversely, less APP was present in the membrane fraction of low-DHA mice, which was consistent with APP being secreted into the cytosolic fraction (Fig. 3B). Together, these data indicated that there was increased APP secretase processing in animals on low-DHA diets, which was reduced in animals supplemented with DHA.

We then sought to determine whether amyloidogenic ( $\beta$ secretase, BACE1) or nonamyloidogenic ( $\alpha$-secretase) pathways were selectively affected by DHA. $\beta$ - and $\alpha$-Secretase activities were indirectly assessed by examining the levels of APP C-terminal fragment products (C99 and C83, respectively) in the membrane fraction in all three groups of mice. Two bands at 11 and $9 \mathrm{kDa}$ were revealed on blots probed with a polyclonal antibody targeting the C-terminal 20 residues (751-770) (Fig. 3C). Cell lysate from B5 cells transfected with the $\beta$-secretase generated C-terminal fragment of APP (C99) was used to identify the $11 \mathrm{kDa}$ band as the product of $\beta$-secretase (Fig. 3C, lane 4 ). This rate-limiting $\beta$-secretase product was significantly increased by $71 \%$ in low-DHA-treated animals compared with those on control chow $(p<0.01)$ (Fig. 3D) and may contribute to increased levels of $A \beta 40$ in these same mice. Supplementing DHA reversed this effect and significantly decreased the protein by $38.3 \%$ when compared with low-DHA diet $(p<0.01)$. The effect of DHA on the $\alpha$-secretase $9 \mathrm{kDa}$ CTF was even greater (Fig. $3 E$ ). Depleting DHA significantly increased the $9 \mathrm{kDa}$ fragment by $96 \%$ compared with animals on control chow $(p<0.001)$. Adding DHA to the diet significantly reduced the level of the $9 \mathrm{kDa}$ band by $54.9 \%$ when compared with those on low-DHA diets $(p<0.001)$.

Additional evidence of an association between DHA levels and secretase activity was found by performing a simple regression analysis between DHA levels (mean percentage of fatty acids) and $\beta$ APP-CTF $(11 \mathrm{kDa})$ and $\alpha$ APP-CTF $(9 \mathrm{kDa})$ ratio levels. Significant negative correlations were found between increasing levels of DHA and reduced amounts of both the $\beta$ APP-CTF $\left(R^{2}=0.37\right.$; $p<0.01)$ and $\alpha$ APP-CTF $\left(R^{2}=0.47 ; p=0.002\right)$ (Fig. 4$)$. Together, these results suggest that dietary DHA limits amyloid production but reduces both amyloidogenic and nonamyloidogenic pathways in these transgenic mice.

\section{BACE expression was unchanged by dietary PUFA}

Because secretase products were elevated with DHA depletion and reduced by dietary DHA, we then investigated effects on secretase expression. In particular, whereas $\alpha$-secretase expression appears more or less constitutive (Sisodia, 1992; Lammich et al., 1999; Lopez-Perez et al., 2001), BACE1 expression in neuronal cells has been reported to be increased by both proinflammatory cytokines (Sastre et al., 2003) and oxidative damage (Tamagno et al., 2002). n-3 PUFAs have been reported to be antiinflammatory (De Caterina et al., 1994; Raederstorff et al., 1996; Simopoulos, 2002) and to reduce oxidative damage (Komatsu et al., 2003), consistent with protein carbonyl reduction with highDHA diets (Calon et al., 2004). Therefore, BACE1 mRNA levels in animals on low- and high-DHA diets were analyzed by real- 
time quantitative PCR. ANOVA analysis revealed no treatment differences in $\mathrm{BACE}$ mRNA expression between the two diet groups (data not shown). Together, these data and our results showing a DHA impact on total APP and $\beta$ CTFs argue for a DHA effect on APP trafficking or secretase activity rather than BACE expression.

\section{Discussion}

In this study, we report that an adequate DHA intake can significantly reduce detergent-insoluble amyloid, plaque burden, and APP processing pathways in aged transgenic animals. Because genetic and environmental factors can impact AD risk, our data point to a causal role for DHA in epidemiological studies, in which sufficient DHA intake is associated with reduced AD risk (Kalmijn et al., 1997; Barberger-Gateau et al., 2002; Morris et al., 2003). Many A $\beta$-lowering treatments, such as $A \beta$ vaccinations, nonsteroidal anti-inflammatory drugs, vitamin $\mathrm{E}$, and statins, were highly efficacious when administered in young APP animals (Lim et al., 2000; Das et al., 2001; Refolo et al., 2001; Jantzen et al., 2002; Sung et al., 2004 ), but $\mathrm{A} \beta$ vaccine and vitamin $\mathrm{E}$ were shown not to work well in older animals. Our data demonstrate that interventions introduced as late as 17 months of age are effective at reducing amyloid burden. Previously, we showed that DHA also has profound effects on synaptotoxicity (Calon et al., 2004). Postsynaptic marker loss and recovery in the DHA-deficient and DHAtreated animals, respectively, could be a result of $A \beta$ accumulation because increased amyloid, particularly $A \beta 42$, is linked to synaptic loss (Mucke et al., 2000; Chin et al., 2004). However, in our studies, synaptic loss occurred without subsequent increases in either total amyloid or $\mathrm{A} \beta 42$ (Fig. 1) in low-DHA mice and were not likely a direct result of total $\mathrm{A} \beta$ accumulation.

We determined previously that brain DHA levels in the Tg2576 mice are reduced $16 \%$ with DHA-depleted diets (Calon et al., 2004). A 16\% DHA loss is reasonable for a 3-5 month treatment, because other studies report that large (50-80\%) (Weisinger et al., 2002) decreases in brain DHA require multiple generations of animals on DHA-depleted diets (Salem et al., 2001). Fatty acid analysis also revealed compensatory increases in another C22 fatty acid, docosapentanoic acid (DPAn-6), a phenomenon typically seen when brain DHA is depleted (Salem et al., 2001). In this current study, we show that adrenic acid levels (docosatetraenoic; 22:4n6) were increased by $15 \%$ with DHA depletion, consistent with previous rat studies (Bourre et al., 1989; Ikemoto et al., 2001; Moriguchi et al., 2001). Whereas DPAn-6 levels have not been evaluated in AD

\section{B Membrane bound APP (22C11)}
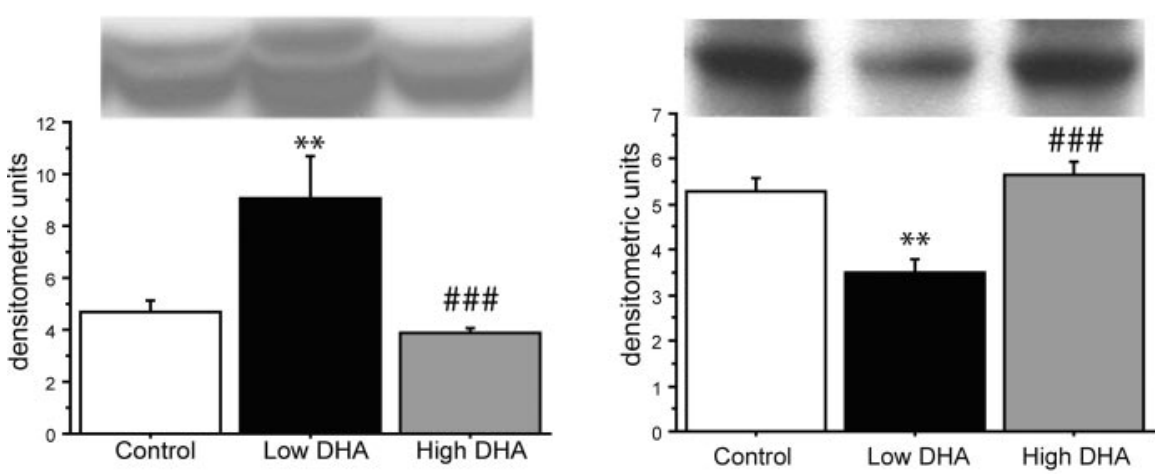

C. APP in membrane fraction
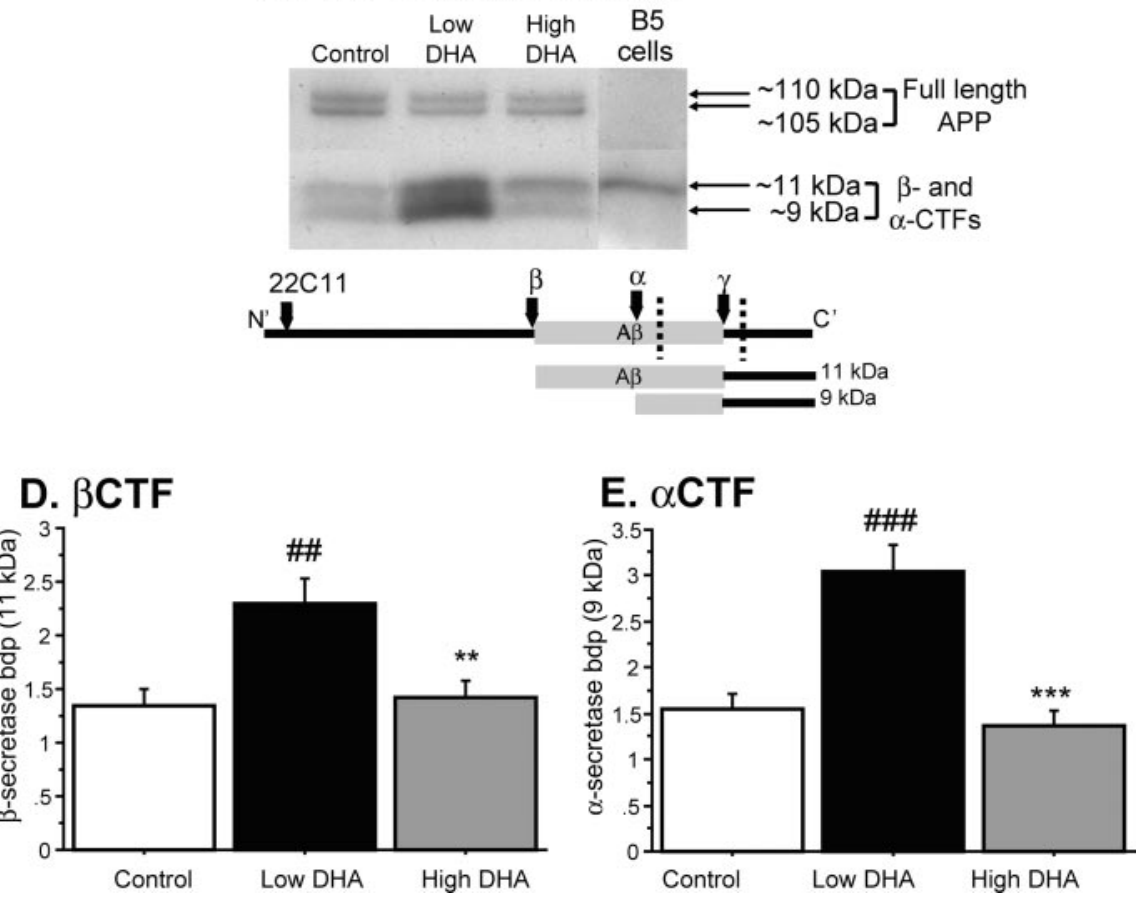

Figure 3. DHA alters full-length APP and processing by $\beta$ - and $\alpha$-secretase. $A$, Levels of APP (22C11) in cytosolic fraction (110 $\mathrm{kDa})$. Measurements were made in the TBS-soluble fraction of control $(n=7)$, low-DHA $(n=4)$, and high-DHA $(n=6)$ groups. Representative examples of APP bands are included above bar graphs. ${ }^{* *} p<0.01$ compared with control group; ${ }^{\# \# \#} p<0.001$ compared with low-DHA group. $B$, Levels of APP (22C11) in lysis buffer fraction (110 kDa). Measurements were made from control, low-DHA, and high-DHA groups. Representative examples of APP bands are included above bar graphs. ${ }^{* *} p<0.01$ compared with control group; ${ }^{\# \#} p<0.001$ compared with low-DHA group. C, Immunoblot of cortex samples and cell lysate from B5 cells stably transfected with APP C99 CTF CEP4 $\beta$ vector (lane 4). Schematic of full-length APP depicts APP fragments recognized by polyclonal antibody against 20 residues at C terminal (751-770). The 110 and $105 \mathrm{kDa}$ bands represent full-length APP. D, Levels of the $\beta$-secretase APP C-terminal fragment product (11 kDa) expressed as a ratio to full-length APP. Measurements were made in the lysis buffer fraction of control $(n=7)$, low-DHA $(n=5)$, and high-DHA $(n=6)$ groups. $\# p<0.01$ compared with control group; ${ }^{* *} p<0.01$ compared with low-DHA group. Error bars represent SE. E, Levels of $\alpha$-secretase APP C-terminal fragment product $\left(9 \mathrm{kDa}\right.$ ) expressed as a ratio to full-length APP ratio in the lysis fraction from the same three groups. ${ }^{\# \#} p<0.001$ compared with control group; ${ }^{* * *} p<0.001$ when compared with low-DHA group. Error bars represent SE.

brains, adrenic acid levels are increased threefold to fourfold in gray matter from AD patients (Skinner et al., 1993), consistent with DHA depletion.

DHA depletion would result in specialized biophysical effects on neuronal membrane structure (Salem and Niebylski, 1995). Recent nuclear magnetic resonance studies directly confirmed that DHA-phospholipids have greater flexibility and less ordered packing of hydrocarbon chains than those containing DPAn-6 (Eldho et al., 2003). One of the best established DHA effects is the 
A. DHA vs. BAPP-CTF (11 kDa)
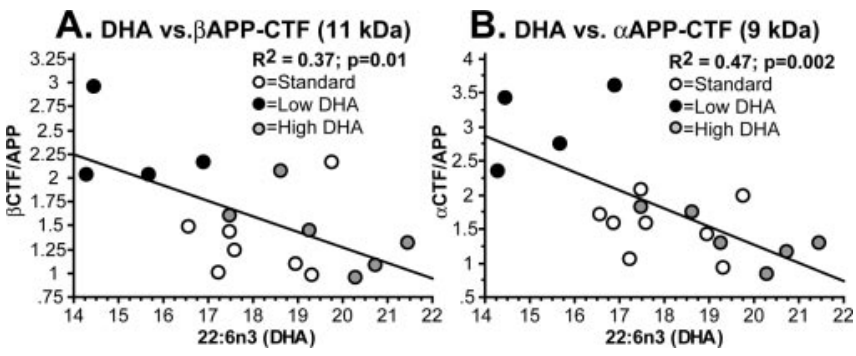

Figure 4. DHA inversely correlates with secretase products. Simple regression was performed between DHA levels (percentage area of total fatty acid) and $\beta$ - and $\alpha$-secretasegenerated C-terminal APP fragment ratios in Figure $3(\boldsymbol{A}, \boldsymbol{B}$, respectively). Significant inverse correlations were found for both APP fragments.

enhancement of retinal G-protein coupling by increasing lateral mobility (Niu et al., 2004). These bulk bilayer properties may alter the lateral movement of proteins, ion channels, and detergent-insoluble lipid rafts. Amyloidogenic APP processing is believed to occur in lipid rafts in the synaptic membrane in which $\beta$ - and $\gamma$-secretases are located (Kawarabayashi et al., 2004). Hence, increasing brain DHA could modify processing pathways by affecting lateral mobility collision rates between APP and secretases. Our data imply that brain DHA content influences APP processing and are summarized in Figure 5. Immunoblot results indicate that high DHA decreased soluble APP $\left(\mathrm{APP}_{\mathrm{s}}\right)$ in the cytosol but increased membrane full-length APP compared with the low-DHA group (Fig. 3). These data are complimentary, suggesting that proteolytic processing of the membrane-bound APP is reduced with DHA. Furthermore, high DHA decreased $\beta$ and $\alpha$-CTFs (Fig. 3), implying that DHA may downregulate $\mathrm{A} \beta$ generation by altering APP trafficking to secretase-containing compartments of the membrane or secretase enzymatic activity itself.

Our findings demonstrate that DHA supplementation decreased total insoluble $A \beta$, including both $A \beta 40$ and $A \beta 42$. Although older animals were used in this study, the $\mathrm{A} \beta$-lowering effect was much larger compared with what we reported with chronic ibuprofen or curcumin treatment beginning at 16 months of age (Lim et al., 2000, 2001). Although the difference was not significant, DHA showed a trend to reduce soluble A $\beta$ (Fig. 1) and may have an effect on this potentially toxic form of amyloid. Interestingly, insoluble and soluble $\mathrm{A} \beta$ are reduced in low-DHA mice, but $A \beta 40$ levels were increased by $65 \%$ compared with control mice. These and other inconsistencies between control and low-DHA chow may be attributable to other differences in the chow other than DHA, such as total fat or cholesterol. Clearly, however, chows that were most closely matched (low and high DHA) showed very consistent results.

DHA is highly enriched in the neuronal or synaptic membrane (Salem, 1989), and its depletion can lead to increased n-6/ n-3 ratios, resulting in inflammation (De Caterina et al., 1994; Raederstorff et al., 1996; Simopoulos, 2002) or excessive oxidative stress (Komatsu et al., 2003), two conditions that enhance A $\beta$ production (Sastre et al., 2003) and are present in AD and transgenic mice (Akiyama et al., 2000; Lim et al., 2000; Pratico et al., 2001; Grundman et al., 2002). Inflammatory cytokines and oxidative stress induce BACE expression and activity (Tamagno et al., 2002; Sastre et al., 2003). DHA supplementation reduces oxidative stress because it decreased oxidized protein levels by $57 \%$ in the Tg2576 mouse (Calon et al., 2004). Although our data rule out an effect on global BACE expression, they do not exclude the possibility that oxidative damage influences local BACE expression or activity around plaques because BACE activity is upregulated in aging Tg2576 and AD (Fukumoto et al., 2004). Therefore, increased brain DHA content could alter $\mathrm{A} \beta$ production by lowering plaque-associated oxidative stress and inflammation.

ELISA revealed that $A \beta 42$ levels in high-DHA mice were lower compared with control and low-DHA chow groups, whereas A $\beta 40$ levels were comparable (Fig. 1). DHA could modulate $\gamma$-secretase activity by suppressing GSK $3 \alpha$ (glycogen synthase kinase) (Phiel et al., 2003). Both GSK3 $\beta$ and GSK3 $\alpha$ are negatively regulated through inhibitory phosphorylation of the PI3K pathway, which is suppressed with DHA depletion (Calon et al., 2004). In this study, we found reduced inhibitory GSK3 $\beta$ (ser9) phosphorylation in low-DHA mice that was restored with high DHA (data not shown) but could not get reliable data on GSK $3 \alpha$ and related $\gamma$-secretase CTF products. Extensive testing of GSK $3 \alpha$ and $\gamma$ CTFs will require new groups of aged mice.

$\mathrm{A} \beta$ reduction could occur via increased $\mathrm{A} \beta$ clearance mechanisms, such as upregulated expression of $\mathrm{A} \beta$ cleaving enzymes such as insulin-degrading enzyme (IDE) or upregulation of $\mathrm{A} \beta$ chaperones such as transthyretin (discussed below). IDE can degrade amyloid and its production, and expression is regulated by the insulin signaling pathway via pAkt and PI3K. DHA-depleted diets and in vitro conditions can downregulate pAkt and PI3K (Akbar and Kim, 2002; Taouis et al., 2002; Calon et al., 2004). Furthermore, we reported recently that decreased PI3K correlates with reduced IDE in Alzheimer brain and in Tg2576 mice on low-DHA diet, and decreased IDE was associated with increased $\mathrm{A} \beta$ monomer levels in low-DHA mice (Zhao et al., 2004). Thus, upregulation of IDE by DHA could reduce $\mathrm{A} \beta$ accumulation in our mouse model.

Interestingly, RT-PCR assays revealed no significant changes in TTR and ApoE expression as a function of diet. ApoE modulates $\mathrm{A} \beta$ metabolism and deposition in transgenic mouse models (Fagan et al., 2002; Holtzman, 2004). DHA could regulate ApoE expression by inducing the transcriptional activity of LXR/RXR (liver X receptor/retinoid X receptor) (de Urquiza et al., 2000), which modulates ApoE expression (Liang et al., 2004; Rebeck, 2004). However, we did not find significant changes in ApoE mRNA levels in high-DHA mice. The absence of TTR induction was unexpected because TTR is markedly elevated in Tg2576 mice (Stein and Johnson, 2002), and its mRNA is induced by dietary fish oil in aged rats (Puskas et al., 2003). These TTR inductions were present in the hippocampus, in which TTR protein is prevalent. Unfortunately, in our study, RNA material was only available from cortex, so it is quite possible that upregulation of TTR by DHA may have occurred in the hippocampus of our mice. It is also possible that eicosapentaenoic acid, the other prominent omega-3 fatty acid in fish oil, induced TTR mRNA levels in aged rats and may partially explain the absence of TTR induction in cortex in our high-DHA mice.

In summary, our data show that altering dietary DHA intake can have profound effects on total insoluble $A \beta$ and $A \beta 42$ levels. These $\mathrm{A} \beta$ changes were associated with decreased plaque burden and coordinate changes in full-length membrane APP, $\mathrm{APP}_{s}$, and APP-CTF levels. Together, it is plausible that brain DHA can limit APP secretase processing, which may occur at multiple levels, including control of membrane order and lateral mobility, oxidative stress, and through inhibition of PI3K and GSK3 $\alpha$. Our data correlate well with epidemiological studies that point to reduced risk of $\mathrm{AD}$ with proper n-3 PUFA intake. Currently, the safety and tolerability of n-3 PUFA ( $4 \mathrm{~g} / \mathrm{d})$ in mild to moderate $\mathrm{AD}$ patients is being tested in Sweden (Y. Freund-Levi, personal 
communication), and two double-blind, placebo-controlled clinical studies are underway to evaluate whether n-3 PUFAs are effective in treating mild AD patients (J. F. Quinn, personal communication and http:// www.alzheimer.ca/english/treatment/trialslisting.html).

\section{References}

Akbar M, Kim HY (2002) Protective effects of docosahexaenoic acid in staurosporine-induced apoptosis: involvement of phosphatidylinositol-3 kinase pathway. J Neurochem 82:655-665.

Akiyama H, Barger S, Barnum S, Bradt B, Bauer J, Cole GM, Cooper NE, Eikelenboom P, Emmerling M, Fiebich BL, Finch CE, Frautschy S, Griffin WS, Hampel H, Hull M, Landreth G, Lue L, Mrak R, Mackenzie IR, Mcgeer PL, et al. (2000) Inflammation and Alzheimer's disease. Neurobiol Aging 21:383-421.

Barberger-Gateau P, Letenneur L, Deschamps V, Peres K, Dartigues JF, Renaud S (2002) Fish, meat, and risk of dementia: cohort study. $\mathrm{Br}$ Med J 325:932-933.

Bourre JM, Durand G, Pascal G, Youyou A (1989) Brain cell and tissue recovery in rats made deficient in $\mathrm{n}-3$ fatty acids by alteration of dietary fat. J Nutr 119:15-22.

Calon F, Lim GP, Yang F, Morihara T, Teter B, Ubeda O, Rostaing P, Triller A, Salem Jr N, Ashe KH, Frautschy SA, Cole GM (2004) Docosahexaenoic acid protects from dendritic pathology in an Alzheimer's disease mouse model. Neuron 43:633-645.

Catalan J, Moriguchi T, Slotnick B, Murthy M, Greiner RS, Salem Jr N (2002) Cognitive deficits in docosahexaenoic acid-deficient rats. Behav Neurosci 116:1022-1031.

Chin J, Palop JJ, Yu GQ, Kojima N, Masliah E, Mucke L (2004) Fyn kinase modulates synaptotoxicity, but not aberrant sprouting, in human amyloid precursor protein transgenic mice. J Neurosci 24:4692-4697.

Connor WE, Neuringer M, Lin DS (1990) Dietary effects on brain fatty acid composition: the reversibility of n-3 fatty acid deficiency and turnover of docosahexaenoic acid in the brain, erythrocytes, and plasma of rhesus monkeys. J Lipid Res 31:237-247.

Das P, Murphy MP, Younkin LH, Younkin SG, Golde TE (2001) Reduced effectiveness of Abeta1-42 immunization in APP transgenic mice with significant amyloid deposition. Neurobiol Aging 22:721-727.

De Caterina R, Cybulsky MI, Clinton SK, Gimbrone Jr MA, Libby P (1994) The omega-3 fatty acid docosahexaenoate reduces cytokine-induced expression of proatherogenic and proinflammatory proteins in human endothelial cells. Arterioscler Thromb 14:1829-1836.

de Urquiza AM, Liu S, Sjoberg M, Zetterstrom RH, Griffiths W, Sjovall J, Perlmann T (2000) Docosahexaenoic acid, a ligand for the retinoid X receptor in mouse brain. Science 290:2140-2144.

Eldho NV, Feller SE, Tristram-Nagle S, Polozov IV, Gawrisch K (2003) Polyunsaturated docosahexaenoic vs docosapentaenoic acid-differences in lipid matrix properties from the loss of one double bond. J Am Chem Soc 125:6409-6421.

Fagan AM, Watson M, Parsadanian M, Bales KR, Paul SM, Holtzman DM (2002) Human and murine ApoE markedly alters A beta metabolism before and after plaque formation in a mouse model of Alzheimer's disease. Neurobiol Dis 9:305-318.

Fukumoto H, Rosene DL, Moss MB, Raju S, Hyman BT, Irizarry MC (2004) Beta-secretase activity increases with aging in human, monkey, and mouse brain. Am J Pathol 164:719-725.
Gamoh S, Hashimoto M, Hossain S, Masumura S (2001) Chronic administration of docosahexaenoic acid improves the performance of radial arm maze task in aged rats. Clin Exp Pharmacol Physiol 28:266-270.

Grant WB, Campbell A, Itzhaki RF, Savory J (2002) The significance of environmental factors in the etiology of Alzheimer's disease. J Alzheimers Dis 4:179-189.

Greiner RS, Catalan JN, Moriguchi T, Salem Jr N (2003) Docosapentaenoic acid does not completely replace DHA in n-3 FA-deficient rats during early development. Lipids 38:431-435.

Grundman M, Grundman M, Delaney P (2002) Antioxidant strategies for Alzheimer's disease. Proc Nutr Soc 61:191-202.

Hashimoto M, Hossain S, Shimada T, Sugioka K, Yamasaki H, Fujii Y, Ishibashi Y, Oka J, Shido O (2002) Docosahexaenoic acid provides protection from impairment of learning ability in Alzheimer's disease model rats. J Neurochem 81:1084-1091.

Holtzman DM (2004) In vivo effects of ApoE and clusterin on amyloid-beta metabolism and neuropathology. J Mol Neurosci 23:247-254.

Ikemoto A, Ohishi M, Sato Y, Hata N, Misawa Y, Fujii Y, Okuyama H (2001) Reversibility of $\mathrm{n}-3$ fatty acid deficiency-induced alterations of learning 
behavior in the rat: level of n-6 fatty acids as another critical factor. J Lipid Res 42:1655-1663.

Jantzen PT, Connor KE, DiCarlo G, Wenk GL, Wallace JL, Rojiani AM, Coppola D, Morgan D, Gordon MN (2002) Microglial activation and $\beta$-amyloid deposit reduction caused by a nitric oxide-releasing nonsteroidal anti-inflammatory drug in amyloid precursor protein plus presenilin-1 transgenic mice. J Neurosci 22:2246-2254.

Kalmijn S, Launer LJ, Ott A, Witteman JC, Hofman A, Breteler MM (1997) Dietary fat intake and the risk of incident dementia in the Rotterdam Study. Ann Neurol 42:776-782.

Kalmijn S, van Boxtel MP, Ocke M, Verschuren WM, Kromhout D, Launer LJ (2004) Dietary intake of fatty acids and fish in relation to cognitive performance at middle age. Neurology 62:275-280.

Kawarabayashi T, Shoji M, Younkin LH, Wen-Lang L, Dickson DW, Murakami T, Matsubara E, Abe K, Ashe KH, Younkin SG (2004) Dimeric amyloid $\beta$ protein rapidly accumulates in lipid rafts followed by apolipoprotein $\mathrm{E}$ and phosphorylated tau accumulation in the $\mathrm{Tg} 2576$ mouse model of Alzheimer's disease. J Neurosci 24:3801-3809.

Komatsu W, Ishihara K, Murata M, Saito H, Shinohara K (2003) Docosahexaenoic acid suppresses nitric oxide production and inducible nitric oxide synthase expression in interferon-gamma plus lipopolysaccharidestimulated murine macrophages by inhibiting the oxidative stress. Free Radic Biol Med 34:1006-1016.

Kyle DJ, Schaefer E, Patton G, Beiser A (1999) Low serum docosahexaenoic acid is a significant risk factor for Alzheimer's dementia. Lipids [Suppl] 34:S245.

Lammich S, Kojro E, Postina R, Gilbert S, Pfeiffer R, Jasionowski M, Haass C, Fahrenholz F (1999) Constitutive and regulated alpha-secretase cleavage of Alzheimer's amyloid precursor protein by a disintegrin metalloprotease. Proc Natl Acad Sci USA 96:3922-3927.

Liang Y, Lin S, Beyer TP, Zhang Y, Wu X, Bales KR, DeMattos RB, May PC, Li SD, Jiang XC, Eacho PI, Cao G, Paul SM (2004) A liver X receptor and retinoid $\mathrm{X}$ receptor heterodimer mediates apolipoprotein E expression, secretion and cholesterol homeostasis in astrocytes. J Neurochem 88:623-634.

Lim GP, Yang F, Chu T, Chen P, Beech W, Teter B, Tran T, Ubeda O, Hsiao Ashe K, Frautschy SA, Cole GM (2000) Ibuprofen suppresses plaque pathology and inflammation in a mouse model for Alzheimer's disease. J Neurosci 20:5709-5714.

Lim GP, Chu T, Yang F, Beech W, Frautschy SA, Cole GM (2001) The curry spice curcumin reduces oxidative damage and amyloid pathology in an Alzheimer transgenic mouse. J Neurosci 21:8370-8377.

Lopez-Perez E, Zhang Y, Frank SJ, Creemers J, Seidah N, Checler F (2001) Constitutive alpha-secretase cleavage of the beta-amyloid precursor protein in the furin-deficient LoVo cell line: involvement of the pro-hormone convertase 7 and the disintegrin metalloprotease ADAM10. J Neurochem 76:1532-1539.

Mitchell DC, Gawrisch K, Litman BJ, Salem Jr N (1998) Why is docosahexaenoic acid essential for nervous system function? Biochem Soc Trans 26:365-370.

Montine TJ, Neely MD, Quinn JF, Beal MF, Markesbery WR, Roberts LJ, Morrow JD (2002) Lipid peroxidation in aging brain and Alzheimer's disease. Free Radic Biol Med 33:620-626.

Moriguchi T, Salem Jr N (2003) Recovery of brain docosahexaenoate leads to recovery of spatial task performance. J Neurochem 87:297-309.

Moriguchi T, Greiner RS, Salem Jr N (2000) Behavioral deficits associated with dietary induction of decreased brain docosahexaenoic acid concentration. J Neurochem 75:2563-2573.

Moriguchi T, Loewke J, Garrison M, Catalan JN, Salem Jr N (2001) Reversal of docosahexaenoic acid deficiency in the rat brain, retina, liver, and serum. J Lipid Res 42:419-427.

Morris MC, Evans DA, Bienias JL, Tangney CC, Bennett DA, Wilson RS, Aggarwal N, Schneider J (2003) Consumption of fish and n-3 fatty acids and risk of incident Alzheimer disease. Arch Neurol 60:940-946.

Mucke L, Masliah E, Yu GQ, Mallory M, Rockenstein EM, Tatsuno G, Hu K, Kholodenko D, Johnson-Wood K, McConlogue L (2000) High-level neuronal expression of $A \beta$ 1-42 in wild-type human amyloid protein precursor transgenic mice: synaptotoxicity without plaque formation. J Neurosci 20:4050-4058.

Mukherjee PK, Marcheselli VL, Serhan CN, Bazan NG (2004) Neuroprotectin D1: a docosahexaenoic acid-derived docosatriene protects human ret- inal pigment epithelial cells from oxidative stress. Proc Natl Acad Sci USA 101:8491-8496.

Niu SL, Mitchell DC, Lim SY, Wen ZM, Kim HY, Salem Jr N, Litman BJ (2004) Reduced G protein-coupled signaling efficiency in retinal rod outer segments in response to $\mathrm{n}-3$ fatty acid deficiency. J Biol Chem 279:31098-31104.

Nourooz-Zadeh J, Liu EH, Yhlen B, Anggard EE, Halliwell B (1999) F4isoprostanes as specific marker of docosahexaenoic acid peroxidation in Alzheimer's disease. J Neurochem 72:734-740.

Phiel CJ, Wilson CA, Lee VM, Klein PS (2003) GSK-3alpha regulates production of Alzheimer's disease amyloid-beta peptides. Nature 423:435-439.

Prasad MR, Lovell MA, Yatin M, Dhillon H, Markesbery WR (1998) Regional membrane phospholipid alterations in Alzheimer's disease. Neurochem Res 23:81-88.

Pratico D, Uryu K, Leight S, Trojanoswki JQ, Lee VM (2001) Increased lipid peroxidation precedes amyloid plaque formation in an animal model of Alzheimer amyloidosis. J Neurosci 21:4183-4187.

Puskas LG, Kitajka K, Nyakas C, Barcelo-Coblijn G, Farkas T (2003) Shortterm administration of omega 3 fatty acids from fish oil results in increased transthyretin transcription in old rat hippocampus. Proc Natl Acad Sci USA 100:1580-1585.

Raederstorff D, Pantze M, Bachmann H, Moser U (1996) Antiinflammatory properties of docosahexaenoic and eicosapentaenoic acids in phorbol-ester-induced mouse ear inflammation. Int Arch Allergy Immunol 111:284-290.

Rebeck GW (2004) Cholesterol efflux as a critical component of Alzheimer's disease pathogenesis. J Mol Neurosci 23:219-224.

Refolo LM, Pappola MA, LaFrancois J, Malester B, Schmidt SD, ThomasBryant T, Tint GS, Wang R, Mercken M, Petanceska SS, Duff KE (2001) A cholesterol-lowering drug reduces $\beta$-amyloid pathology in a transgenic mouse model of Alzheimer's disease. Neurobiol Dis 8:890-899.

Salem Jr N (1989) Omega-3 fatty acids: molecular and biochemical aspects. In: New protective roles of selected nutrients in human nutrition (Spiller G, Scala J, eds), pp 109-228. New York: Liss.

Salem Jr N, Niebylski CD (1995) The nervous system has an absolute molecular species requirement for proper function. Mol Membr Biol 12:131-134.

Salem Jr N, Reyzer M, Karanian J (1996a) Losses of arachidonic acid in rat liver after alcohol inhalation. Lipids [Suppl] 31:S153-S156.

Salem Jr N, Wegher B, Mena P, Uauy R (1996b) Arachidonic and docosahexaenoic acids are biosynthesized from their 18-carbon precursors in human infants. Proc Natl Acad Sci USA 93:49-54.

Salem Jr N, Litman B, Kim HY, Gawrisch K (2001) Mechanisms of action of docosahexaenoic acid in the nervous system. Lipids 36:945-959.

Sastre M, Dewachter I, Landreth GE, Willson TM, Klockgether T, van Leuven F, Heneka MT (2003) Nonsteroidal anti-inflammatory drugs and peroxisome proliferator-activated receptor- $\gamma$ agonists modulate immunostimulated processing of amyloid precursor protein through regulation of $\beta$-secretase. J Neurosci 23:9796-9804.

Simopoulos AP (2002) Omega-3 fatty acids in inflammation and autoimmune diseases. J Am Coll Nutr 21:495-505.

Sisodia SS (1992) Beta-amyloid precursor protein cleavage by a membranebound protease. Proc Natl Acad Sci USA 89:6075-6079.

Skinner ER, Watt C, Besson JA, Best PV (1993) Differences in the fatty acid composition of the grey and white matter of different regions of the brains of patients with Alzheimer's disease and control subjects. Brain 116:717-725.

Soderberg M, Edlund C, Kristensson K, Dallner G (1991) Fatty acid composition of brain phospholipids in aging and in Alzheimer's disease. Lipids 26:421-425.

Stein TD, Johnson JA (2002) Lack of neurodegeneration in transgenic mice overexpressing mutant amyloid precursor protein is associated with increased levels of transthyretin and the activation of cell survival pathways. J Neurosci 22:7380-7388.

Sung S, Yao Y, Uryu K, Yang H, Lee VM, Trojanowski JQ, Pratico D (2004) Early vitamin E supplementation in young but not aged mice reduces Abeta levels and amyloid deposition in a transgenic model of Alzheimer's disease. FASEB J 18:323-325.

Suzuki H, Park SJ, Tamura M, Ando S (1998) Effect of the long-term feeding of dietary lipids on the learning ability, fatty acid composition of brain 
stem phospholipids and synaptic membrane fluidity in adult mice: a comparison of sardine oil diet with palm oil diet. Mech Ageing Dev 101:119-128.

Tamagno E, Bardini P, Obbili A, Vitali A, Borghi R, Zaccheo D, Pronzato MA, Danni O, Smith MA, Perry G, Tabaton M (2002) Oxidative stress increases expression and activity of BACE in NT2 neurons. Neurobiol Dis 10:279-288.

Taouis M, Dagou C, Ster C, Durand G, Pinault M, Delarue J (2002) N-3 polyunsaturated fatty acids prevent the defect of insulin receptor signaling in muscle. Am J Physiol Endocrinol Metab 282:E664-E671.

Weisinger HS, Armitage JA, Jeffrey BG, Mitchell DC, Moriguchi T, Sinclair AJ, Weisinger RS, Salem Jr N (2002) Retinal sensitivity loss in thirdgeneration n-3 PUFA-deficient rats. Lipids 37:759-765.
Yamada T, Kadekaru H, Matsumoto S, Inada H, Tanabe M, Moriguchi EH, Moriguchi Y, Ishikawa P, Ishikawa AG, Taira K, Yamori Y (2002) Prevalence of dementia in the older Japanese-Brazilian population. Psychiatry Clin Neurosci 56:71-75.

Youyou A, Durand G, Pascal G, Piciotti M, Dumont O, Bourre JM (1986) Recovery of altered fatty acid composition induced by a diet devoid of n-3 fatty acids in myelin, synaptosomes, mitochondria, and microsomes of developing rat brain. J Neurochem 46:224-228.

Zhao L, Teter B, Morihara T, Lim GP, Ambegaokar SS, Ubeda OJ, Frautschy SA, Cole GM (2004) Insulin-degrading enzyme as a downstream target of insulin receptor signaling cascade: implications for Alzheimer's disease intervention. J Neurosci 24:11120-11126. 